\title{
The analysis of GDI engine soot emission based on spray and ignition timing tactics
}

\author{
LIN Man-qun ${ }^{1,2, a}$, ZHOU Peng ${ }^{1,2, b}$, QIN Jing ${ }^{1,2, c}$, PEI Yi-qiang ${ }^{2, d}$, PAN \\ Suo-zhu ${ }^{2, ~ e ~}$
}

(1, Internal Combustion Engine Research Institute, Tianjin University, Tianjin, china 300072);

(2, State Key Laboratory of Engines, Tianjin University, Tianjin, china 300072)

atomlin@tju.edu.cn, bsyuuhou0205@yahoo.com.cn, 'cqinjing@tju.edu.cn, dpeiyq@tju.edu.cn, esuozhup@163.com

Keywords: gasoline direct injection engine, spray strategy, ignition timing, soot emission

\begin{abstract}
By the means of the simulation companied by the experiment of GDI engine, the distribution of fuel mixture and soot emission were taken into consideration under different ignition timing. In one injection model, the ignition retard can lessen the soot emission. Two stage spray in cold start, which contributes to catalyst heating operation immediately but triggers a deteriorative performance concerning the soot emission, could be ameliorated by ignition retard. The result shows that the appropriate spray and ignition timing strategy could contribute to the optimization of distribution of air-fuel ratio, streamlining of the circulation variation, the efficient performance, broad confines of extreme circumstance and reduction of the soot emission.
\end{abstract}

\section{Introduction}

GDI technology can bring about significant economic benefits and power promotion. Nevertheless the direct injection pattern triggers the worse soot emission.

PM emissions from GDI engine are higher than PFI engines for the following reasons [1]:

1) Less time is available for evaporation of the fuel and mixture preparation.

2) Stratified operation produces high levels of PM emissions because of the presence of locally rich regions.

3) Even operating with homogeneous mode, the PM emissions are higher than from a PFI engine because of fuel impingement of the combustion chamber surfaces.

The diversities of spray and ignition timing strategy are the key parameters that have effect on the soot emission of GDI engine. The paper studied the effect on the GDI soot emission under homogeneous and stratified mode, besides the two stages spray tactics aiming to improve the cold start performance was verified to be an optimum operation pattern but would bring on more soot emission on the occasion of cold start. A prominent and permanent conjunction was traced of the two stage injection combined with proper ignition timing logic. Detailed analysis was carried out with comprehensive utilization of simulation companied by the experiment.

\section{Calculation model}

Discrete droplet model was exploited in spray simulation, which comprised the submodel, specifically the vaporization, breakdown, collision and aggregation, turbulence diffusion of spray droplet. The vaporization model was Dukowicz and Huh Gosman served as the recrushing model and Bai Gosman, suitable for GDI, as the impingement model controlled by the Weber and Laplace. Coherent flamelet served as the combustion model and Frolov Kinetic Model supported the soot emission verified via experiment.

\section{Experimental system}


4-cylinder 4-stroke Miller circulation GDI engine was applied in experiment. The detailed engine parameters displays in Table 1.

Table 1 Experimental engine basic parameter

\begin{tabular}{c|c|c|c}
\hline bore $\times$ stroke $(\mathrm{mm})$ & $77.8 \times 18.8$ & Compression ratio & 12 \\
\hline Displacement(L) & 1.498 & Injection pressure & $10 \mathrm{MPa}$ \\
\hline Cod length $(\mathrm{mm})$ & 153.3 & & \\
\hline
\end{tabular}

The experimental systems, shown in Fig.1, consisted of GDI engine, in-cylinder combustion data acquisition system, PM size distribution meter, PM microcosmic feature acquisition apparatus, PAHs acquisition apparatus, gas emission analysis apparatus or so. The mass of GDI soot was obtained via filter paper catching and scale weighing.
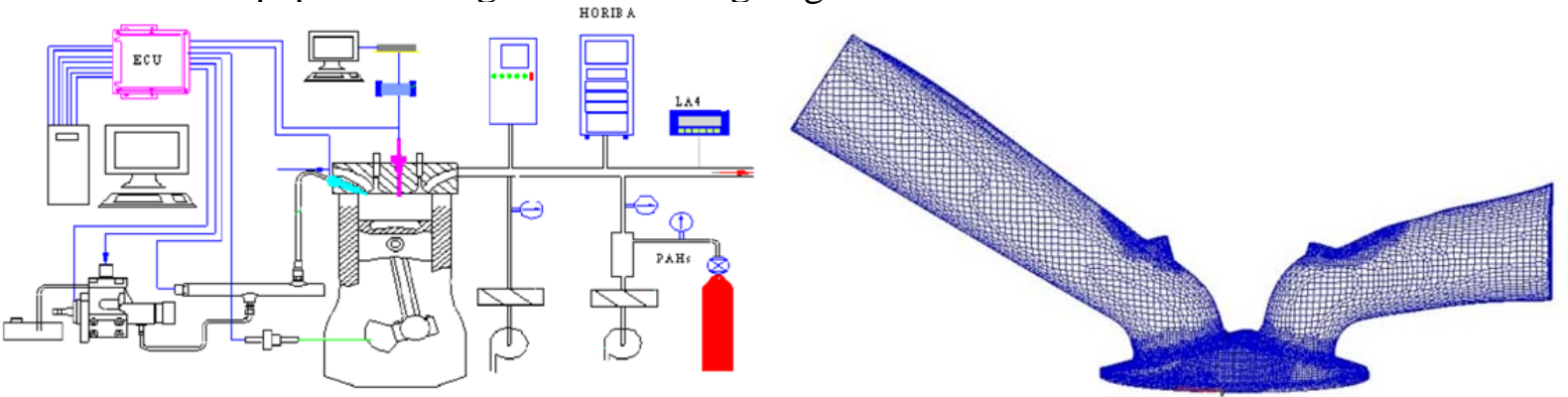

Fig.1 sketch map of GDI PM sampling analysis platform (left)

Fig. 2 3D model in exhaust TDC (right)

\section{Experimental results}

The PM value that filter paper caught shows in Table2

Table 2 soot emission in different ignition angle

\begin{tabular}{|l|c|c|c|}
\hline Ign. angle & -15 & -25 & -40 \\
\hline PM value & 0.061 & 0.064 & 0.082 \\
\hline
\end{tabular}

Establishment of 3D simulation model

In line with experiment engine established the integrated 3D model that consisted of the intake and exhaust ports, valves, chamber, piston top which was generated into movement mesh as the Fig. 1.

\section{Calibration of combustion model}

Fig. 4 showed the comparison of cylinder pressure between experiment and simulation under $2000 \mathrm{r} / \mathrm{min}$, torque $37.1 \mathrm{Nm}$, air-fuel ratio 14.7.

The simulation curve agreeing with the experiment verified that the model was in a position to reflect the work process of GDI engine exactly.

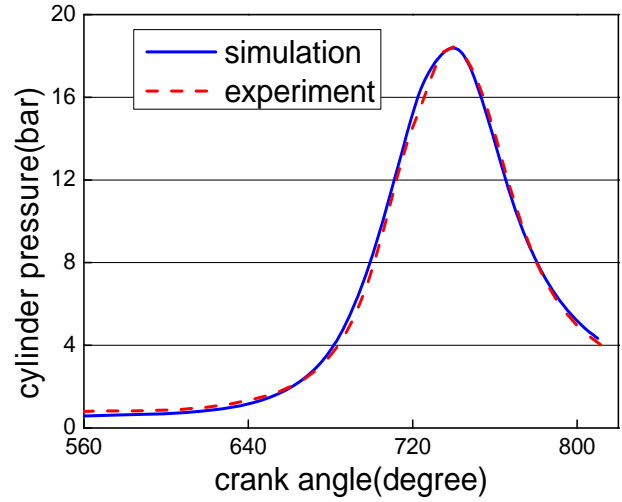

Fig. 3 comparison of cylinder pressures

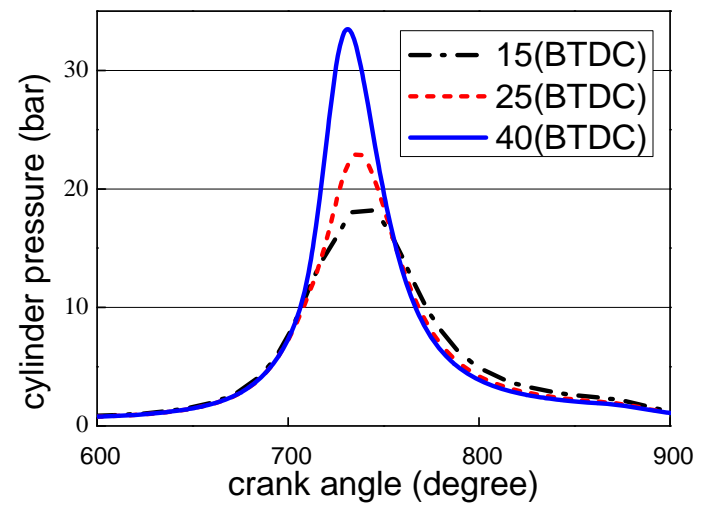

Fig.4 Cylinder pressure in ignition timings

\section{Simulative analysis on soot generation}


It is shown in Fig.7 that higher cylinder pressure presents with ignition angle advanced.

\section{The soot formation process under different ignition angles}

The soot distribution of ignition timing of $-15,-25,-40$, respectively during the crank angle 680-810 ${ }^{\circ} \mathrm{CA}$ was shown in the table 3 . The combustion temperature determines the amount of soot production for the stimulative effect of high temperature on soot. The soot starts to generate after ignition. Following the spread of flame, the place of soot disperses around with the initial soot burnt up. As the piston moves down, the temperature in cylinder declines, the oxidation speed of soot slow down with the thin flame especially in the region close to the colder wall where soot left. Ignition -40 The case of ignition -40 triggers the highest temperature and most soot formation in pressure peak, as is shown in Fig.4 and 5, and inevitably results in the insufficient evaporation of fuel due to the least time from injection and ignition as well as the quickly declining expansion temperature which fails to oxidize the soot formed. Ignition -15 has the most reasonable potential by comprehensively considering about the combustion stability and soot mount. It is toluene that is in gasoline, one of the main matters sensitive on variation of soot emission in changing ignition angle which is responsible for the gasoline soot emission [2]. In accordance with the experiment data, the value of particle emission in the ignition timing -15, -25, -40 degree was 0.061, 0.064, $0.082 \mathrm{~g} / \mathrm{kwh}$ respectively shown in Table 2. The process of soot generation shows in Fig.6 which agrees with the experimental results exactly.

Table 3 Soot distribution of ignition timing of $15,25,40^{\circ} \mathrm{CA}$ (BTDC)

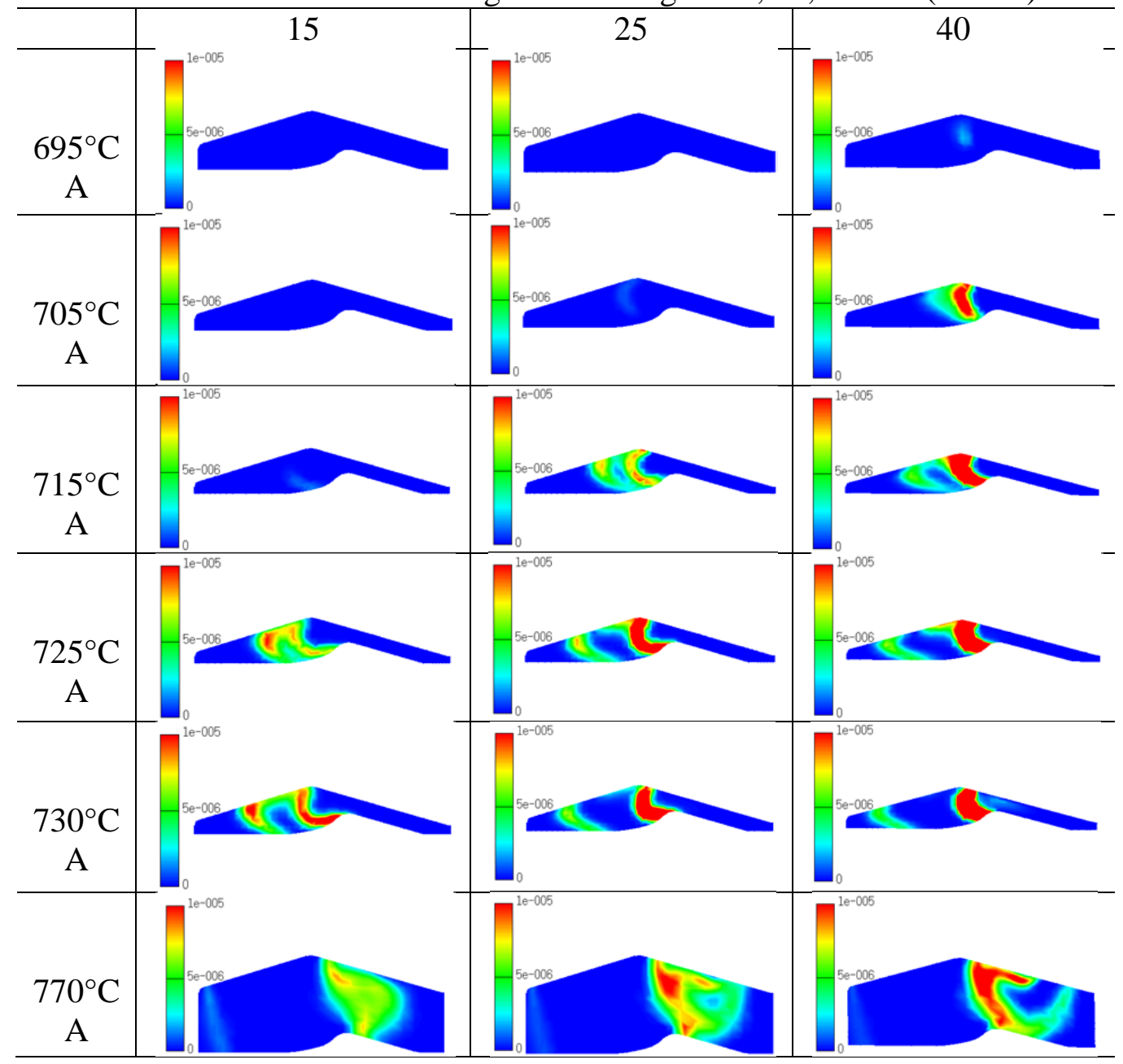




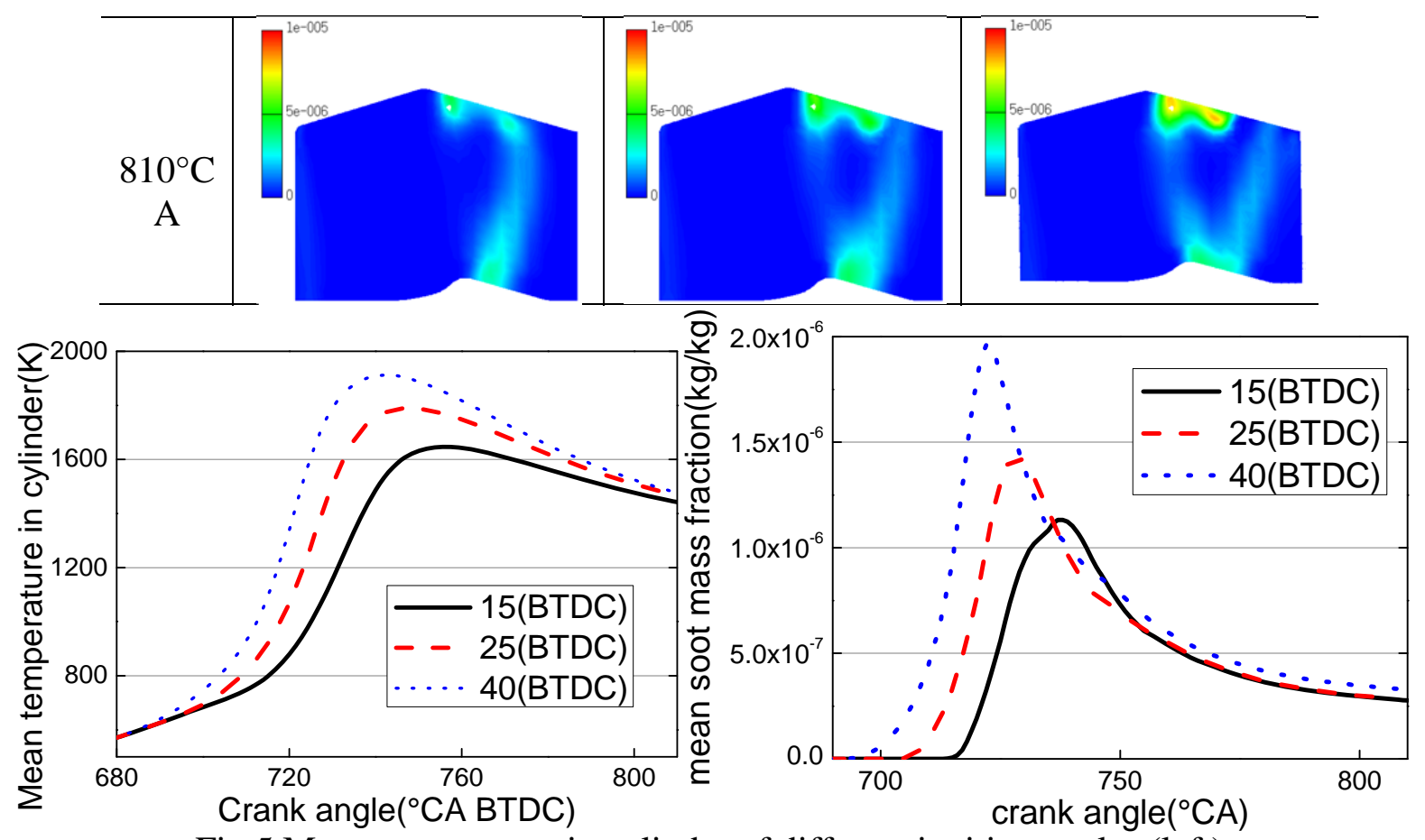

Fig.5 Mean temperature in cylinder of different ignition angles (left)

Fig.6 Soot formation process in different ignition timing of $-15,-25,-40$ (right)

\section{Two stage spray}

The pilot injection is applied during the intake stroke and the rest of the fuel at the end of the compression stroke then ignited after some delay. The main injection during intake stroke is to make a homogeneous mixture preparation within a combustion chamber, and the second injection just before a spark ignition is to supply a rich stratified mixture near the spark plug, which contributes to the catalyst heating operation immediately [3].

A comparison was carried through between one stage injection and two phase injection with common and cold start considered respectively, which was shown in Table 4.

Table 4 Different spray and ignition tactics

\begin{tabular}{c|c|c|c|c|c}
\hline & & first & second & ratio & Ign. \\
\hline \multirow{2}{*}{ normal } & Case1 & 440 & 600 & $7: 3$ & 705 \\
\cline { 2 - 6 } normal & Case2 & 440 & 600 & $7: 3$ & 715 \\
\hline \multirow{2}{*}{$\begin{array}{c}\text { cold } \\
\text { cold }\end{array}$} & Case3 & 440 & 600 & $7: 3$ & 705 \\
\cline { 2 - 6 } & Case4 & 440 & 600 & $7: 3$ & 715 \\
\hline normal & Case5 & 440 & - & - & 705 \\
\hline
\end{tabular}

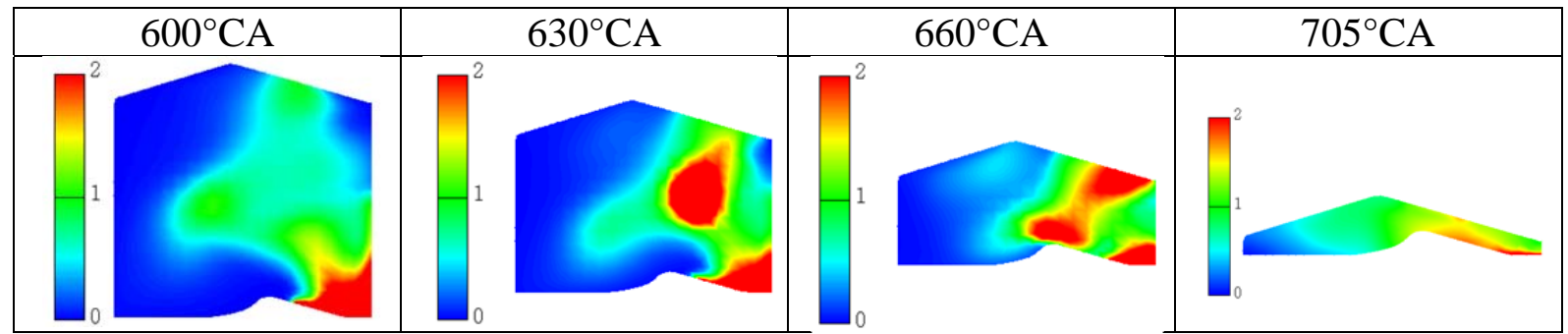

Fig.7 the fuel-air ratio distribution of case1, 2

Two cases of cold start were taken into account. The rotate speed was 300r/min and the boundary temperature was set in $268 \mathrm{~K}$.

As shown in Fig.8 and 9, the adoption of two stage injection with proper statics will contribute to the evaporation of fuel that the reduced first injection lessens the accumulation value due to wall film matter and the second injection evaporates quickly on account of the high temperature and violent turbulence, as shows in case 1 and 2 of the Fig.7. Ignition retard could only ameliorate the 
soot emission within limit, which is shown in the comparison between case 1 and 2 that the retard ignition brings about ambience of low temperature, which fails to oxidize the soot formed and triggers more soot emission. Nevertheless, on the occasion of cold start, the worse evaporation results in the non-uniform and dense mixture that impel the generation of soot and the cold ambience of the place far from the core flame area cooling down and leaving soot there as shown in case 3, which, however, can be improved by the means of ignition retard for the retard ignition can offer more change for fuel to evaporate and the steadier combustion.
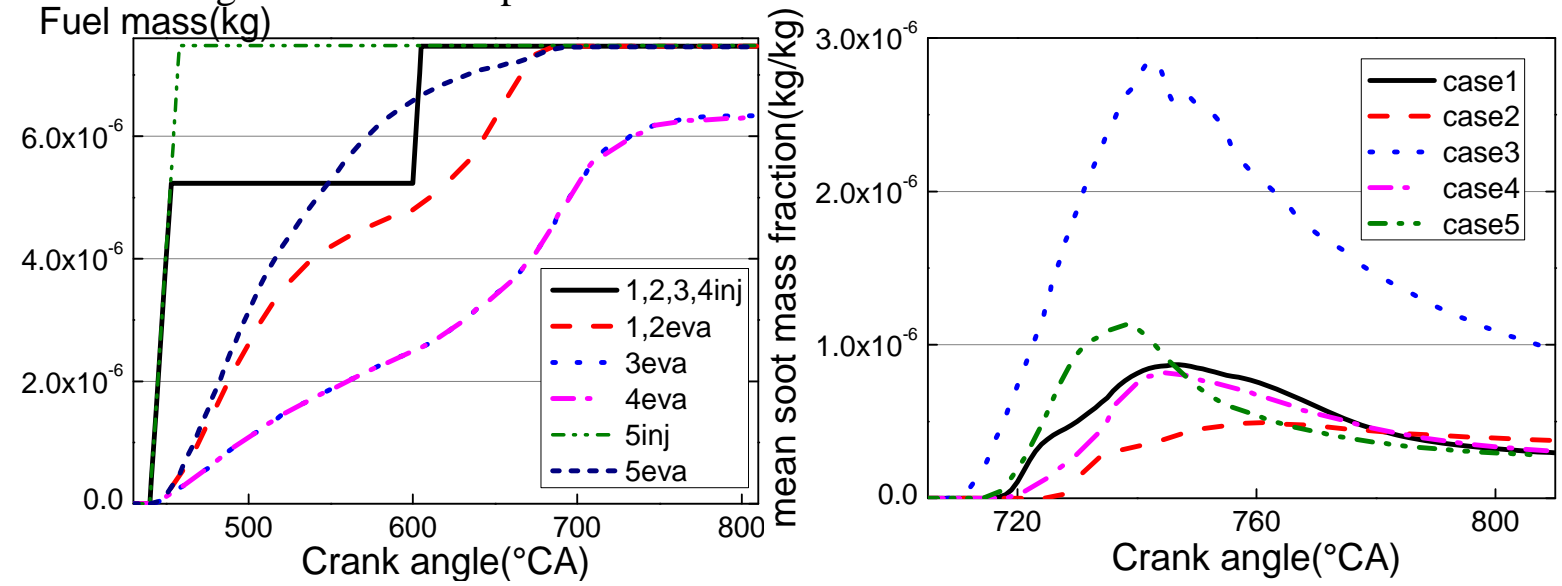

Fig.8 the injection and evaporation mass of the fuel in 5 cases (left)

Fig.9 Soot formation process of the 6 cases (right)

\section{Results}

1) The soot magnitude decreases in accordance with the ignition angle retard which depends on the local temperature, the concentration and duration of oxygen. The high temperature and thin oxygen after ignition triggers the production of soot then the consumption of soot also requires proper temperature and a plenty of oxygen. The narrow space in cylinder and irrational piston top structure that hampers the spread of flame as well as the cold wall will hinder the oxidation of soot.

2) Two stage of injection contributes to the catalyst heating operation immediately but triggers more soot emission in cold start due to dense mixture that impel the generation of soot and the cold ambience of the place far from the core flame area cooling down and leaving soot there.

3) Comprehensively considering on the ignition timing and matter of two stage injection of cold start, the ignition angle regard will alleviate the explosive temperature boost and atomize the spray more thoroughly, as ameliorates the reduction of soot emission.

\section{Acknowledgement}

The research is supported by National Natural Science Foundation of China (50976076).

\section{Reference}

[1] Philip Price and Richard Stone, Tony Collier and Marcus Davies. Particulate Matter and Hydrocarbon Emissions Measurements: Comparing First and Second Generation DISI with PFI in Single Cylinder Optical Engines. 2006 SAE World Congress Detroit, Michigan April 3-6, 2006.

[2] Heywood JB, Internal Combustion Engine Fundamentals, Mc Graw-Hill Book Company. (1988).

[3] Cha-Lee Myung, Juwon Kim, Kwanhee Choi, In Goo Hwang, Simsoo Park. Comparative study of engine control strategies for particulate emissions fromdirect injection light-duty vehicle fueled with gasoline and liquid phaseliquefied petroleum gas (LPG). 